\title{
Prevalence of Contagious Diseases of School Going Children in Bangladesh
}

\author{
Khan Md. Murtaja Reza Linkon1*, Utpal Kumar Prodhan1, Md. Liton1, Md. Kamrul Islam1, \\ Laisa Ahmed Lisa², Dipak Kumar Paul ${ }^{3}$ \\ ${ }^{1}$ Department of Food Technology and Nutritional Science, Mawlana Bhashani Science and Technology \\ University, Tangail, Bangladesh \\ ${ }^{2}$ Department of Microbiology, Jagannath University, Dhaka, Bangladesh \\ ${ }^{3}$ Department of Applied Nutrition and Food Technology, Islamic University, Kusthia, Bangladesh \\ Email: ${ }^{\text {murtaja.kus@gmail.com }}$
}

Received 5 April 2015; accepted 30 June 2015; published 3 July 2015

Copyright (C) 2015 by authors and Scientific Research Publishing Inc. This work is licensed under the Creative Commons Attribution International License (CC BY). http://creativecommons.org/licenses/by/4.0/

(c) (i) Open Access

\begin{abstract}
Children are becoming increasingly vulnerable to contagious disease around the world. It also leads to chronic health problems. This cross-sectional study aimed to determine the prevalence of contagious diseases in children of 5 - 12 years from five government primary schools (class II to V) in Tangail City, Bangladesh using multistage sampling method. Data were collected using a carry home questionnaire and diseases screening examination was done in the school. Prevalence of common contagious diseases was calculated. A total of 84 students were screened to have contagious diseases by clinical examination, giving a prevalence rate of $8.76 \%$ from 958 participated school children. The prevalence of contagious disease among the affected children in the study was found $30.95 \%$ for scabies, while $20.24 \%$ for influenza and $7.14 \%, 9.52 \%, 15.48 \%, 5.95 \%$, \& $10.71 \%$ for typhoid, chicken pox, measles, pneumonia, and whooping cough, respectively. Anthropometric measurements were recorded which indicated that $48.8 \%$ of children were wellnourished and $21.4 \%, 17.9 \%, \& 11.9 \%$ of children were underweight, stunted, and wasted, respectively. However, these data are extremely important to define the problem and to design proper intervention strategies.
\end{abstract}

\section{Keywords}

School Children, Contagious Diseases, Nutritional Status, Cross Sectional Study, Prevalence

\section{Introduction}

The prevalence of contagious diseases is increasing throughout the world at an unprecedented rate. A contagious

${ }^{*}$ Corresponding author.

How to cite this paper: Linkon, K.Md.M.R., Prodhan, U.K., Liton, Md., Islam, Md.K., Lisa, L.A. and Paul, D.K. (2015) Prevalence of Contagious Diseases of School Going Children in Bangladesh. Journal of Biosciences and Medicines, 3, 17-24. http://dx.doi.org/10.4236/jbm.2015.37003 
disease is a sub section of infectious diseases which are easily transmitted by the physical contact with one person to another suffering or by their secretions or objects touched by them or by surrounding environment. Genetic, environmental and developmental factors have been shown to contribute significantly to the development of contagious diseases [1]. In developing countries, contagious diseases have also been linked to extreme and rapid changes in lifestyle including urbanization and rapid economic development. Childhood contagious diseases are most likely results from an interaction of nutritional, psychological, familial and physiological factor [1] [2]. One study shows that, in Africa, one in every ten children aged 6 to 12 years old is affected by contagious diseases [3]. Furthermore, in both developed and developing countries proportionately girls are more susceptible than boys to contagious diseases. Different types of contagious diseases that commonly seen are given below:

Pneumonia: Acute respiratory infections (ARIs) are responsible for many deaths. Pneumonia, the deadliest ARI, kills more children than any other contagious diseases. Most of these deaths (99\%) occur in developing countries. Yet in industrialized countries childhood deaths from pneumonia are rare. Pneumonia often affects children with low birth weight or those whose immune systems are weakened by malnutrition or other diseases.

Influenza (flu): This is a virus that causes fever, body aches, stomach symptoms (especially in children) and tiredness. Incubation period is 1 to 4 days.

Malaria: Malaria kills over one million people a year-most of them young children. Most malaria deaths occur in sub-Saharan Africa, where malaria accounts for one in five of all childhood deaths. Malaria can rapidly overwhelm a young child causing high fever, convulsions and breathing difficulties. With the onset of cerebral malaria - an acute form of the disease, the child lapses into a coma and may die within 24 hours.

Diarrhea: Diarrheal diseases especially watery diarrhea affect nearly two million children among the age of 1 12 years. Children die simply because their bodies are weakened often through rapid loss of fluids and undernourished through lack of food. Diarrheal diseases impose a heavy burden on developing countries-accounting for 1.5 billion bouts of illness a year in children under five. In certain developing countries, epidemics of diarrheal diseases such as cholera and dysentery strike down adults and children alike. Other major diarrheal diseases include typhoid fever and rotavirus which are the main cause of severe dehydrating diarrhea among children.

Measles: Measles is the most contagious disease known to man. It is a major childhood killer in developing countries accounting for about 900,000 deaths a year [4].

Chicken pox: This is a virus that causes itchy blisters and fever. The incubation period is 10 to 21 days. Calamine lotion and oatmeal baths can help with the itching.

Whooping cough (pertussis): This is a highly contagious disease that causes severe coughing attacks and vomiting after coughing. Incubation is usually 7 to 10 days, but can take up to 42 days.

Scabies: These are parasites. Small mites infest the skin, causing pimple like irritation and intense itching. Incubation period is 4 to 6 weeks if the child never had [5] [6].

Contagious disease surveillance deals with contagious diseases (also called communicable diseases), which are diseases capable of being transmitted from one person or species to another. Health information-a key ingredient in policy formation and program planning-has often proven to be a scarce commodity in places where it is needed most [7]. These are often spread through direct contact with an individual, contact with the bodily fluids of infected individuals, or with objects that the infected individual has contaminated. Surveillance means to watch over with great attention, with authority and often with suspicion [8]. The commonly used definition for surveillance is a process of watchfulness over health events which may occur in a population. It has been defined as "the ongoing and systematic collection, analysis, interpretation of health data in the process of describing and monitoring a health event" with the objective of supporting the planning, implementation and evaluation of public health interventions and program [9]. More specifically, communicable disease surveillance is the continuous monitoring of the frequency and the distribution of disease and deaths due to infections that can be transmitted from human to human or from animals, food, water or the environment to humans, and the monitoring of risk factors for those infections [10]. This definition means information for a real action. Surveillance systems are networks maintaining their operation at different levels and providing information for disease prevention and control. Effective communicable disease control needs effective response systems, which basically depend on effective disease surveillance. An effective surveillance system is a corner stone in providing information for action on priority communicable diseases and plays a major role in public health decision-making and provides data, which can be used for priority setting, policy decisions, planning, implementation, resource mobilization and allocation, prediction and early detection of epidemics [11]. A surveillance system can also be 
used for monitoring, evaluation and improvement of disease prevention and control program. So it provides essential information for cost-effective health care delivery. Among the easiest medical conditions contagious disease is one of the most alarming public health issues. It also leads to chronic health problems. The present epidemiological study has been undertaken to study the contagious disease among the primary school children in Tangail city. But no information on the prevalence of contagious disease of Tangail among children has been found in the published literature. These data are extremely important to define the problem and to design proper intervention strategies. Even though, it only provides rough estimates of the prevalence of contagious disease, but still remains undetected. However, the study provides baseline data on the prevalence of contagious disease as well as their associated risk factors in the Tangail city children of Bangladesh.

\section{Methods and Materials}

The current study was conducted by using multistage sampling method to determine the prevalence of contagious diseases in children of 5 - 12 years from five government primary schools (class II to V) in Tangail, Bangladesh. Tangail city corporation area, an urban area with a population of 3.6 million and 1477 primary school [12], which was focused. Multistage sampling including cluster sampling was used to select the desired sample with assistance of registered Physician. Five schools were selected randomly from each stratum. Gender based stratification was not considered. Total 958 children were randomly selected and 84 children were screened out having contagious diseases. They were further classified into males (54) \& females (30). The study was approved by the Institutional Ethics committee. Consent was taken from the institutional heads of the selected schools and the District Educational Officer. Informed consent was also obtained from the parents of the children.

\subsection{Study Overview}

Data was collected using a semi structured, carry home questionnaire which was pretested and modified. Mothers or caregivers of selected children who were willing to and participate in the study were interviewed for collecting the desired information. Information on selected socio-demographic characteristics: age of children, caste, religion, socio-economic status (SES), educational status of mother; Contagious disease information: respondent have idea about contagious disease, causes, type of service which they provide, time period of recovery from disease, role of respondents Family during disease occurred etc. Anthropometric measurements included height in meters; measured to the nearest $0.5 \mathrm{~cm}$ using a measuring tape and weight in kg; measured to the nearest $0.5 \mathrm{~kg}$ using a bathroom scale. Body Mass Index was also calculated.

\subsection{Data Analysis}

Appropriate analytical techniques were used depending on the variables or the characteristics being considered. Descriptive and inferential statistical techniques were used for quantitative data including socio-economic and demographic information, anthropometry, contagious disease information to generate frequencies and percentages using statistical package for social sciences (SPSS) Version 16.0. The anthropometric data obtained were used to determine the mean weight for age, mean weight for age, mean weight for height were compared with WHO Reference standard (2007).Three standard indices of physical growth that describe the nutritional status of children were considered for the anthropometric analyses, those were weight-for-age (underweight), height-forage (stunting) and weight-for-height (wasting). Each of these indices is expressed in terms of the number of standard deviation units (Z-score) from the median of the NCHS/WHO international reference population and provides somewhat different information about the nutritional status of children.

\section{Result}

A total of 958 students were included in the study. According to presented data 84 school children among all participants were found to have contagious disease. The overall prevalence of contagious disease was $8.76 \%$ whereas $91.24 \%$ had no diseases (Figure 1 ).

Out of 84 respondent, prevalence of contagious disease were $30.95 \%$ for scabies, $20.24 \%$ for influenza and $7.14 \%, 9.52 \%, 15.48 \%, 5.95 \% \& 10.71 \%$ for typhoid, chicken pox, measles, pneumonia, whooping cough respectively. Scabies and influenza were more prevalence than others (Figure 2). 


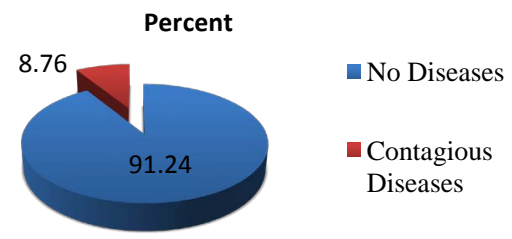

Figure 1. Overall percentage of contagious diseases.

Percent
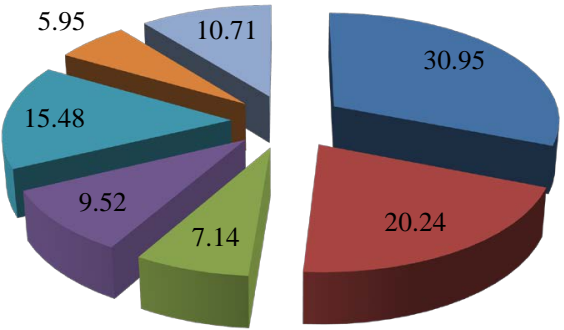

- Scabies
- Influenza
- Typhoid
— Chicken pox
- Measles
- Pneumonia
— Whooping cough

Figure 2. Distribution of children according to their contagious diseases.

Time period of recovery from contagious disease that depends on different factor such as type of treatment, types of care by family, patient lifestyle etc. In this study about $46.7 \%$ patient recoveries from contagious disease within 6 - 10 days. About 20\% and 13.3\% patient recover from contagious diseases within 2 - 5 days and 11 - 15 days respectively. Some patient takes more time for complete recovery (Figure 3).

Figure 4 shows that, type of service which they provide when contaminated with different types of contaminated disease. In this study most of the patient (53.3\%) takes curative treatment during affected by contagious disease. Some are take preventive (20\%) and some take both curative and preventive (26\%).

\section{Socio-Demographic Determinants of Contagious Disease}

The Frequencies and percentages of Hygiene and sanitary condition of Respondents family shown in Table 1; among them about $48.8 \%$ satisfactory hygiene and sanitary condition of respondents home toilet, Environment of respondents school were $61.9 \%$ satisfactory and $21.4 \%$ unhygienic, Respondent family washes utensils mainly with soap/bar 36.9\%, $17.9 \%$ by detergent, $17.9 \%$ by ash. Respondent washed their cloths 6 - 9 day interval (48.8\%) and 3 - 5 days interval (29.8\%). Maximum respondent used soap during bathing everyday (71.4\%) and some are one times in two days (25.0\%). Most of the respondent take bathe in tube-well (54.8\%) \& some in pond (22.4\%). Maximum respondent family (40\%) gives extra care to infected person.

In Table 2 it indicates $48.8 \%$ child are well-nourished and $21.4 \%, 17.9 \%$ \& $11.9 \%$ child were underweight, stunted, \& wasted respectively in infected group. About $26 \%$ child suffer from vitamin deficiency, about 14 suffer from mineral deficiency and $13.3 \%$ suffer from both vitamin and mineral deficiency but about $50 \%$ child have no vitamin and mineral deficiency. About $38.1 \%$ respondent takes meal every day in four times and $25 \%$, $20.2 \%$ respondent takes meal every day in five times and three times respectively. Maximum respondent (31\%) takes tiffin at the school with biscuit, cake. Some such as $17.9 \%$ and $14.3 \%$ takes tiffin at the school with Chocolates, candy and Puffed rice, bread respectively. About $21.4 \%$ child takes no tiffin at the school.

Table 3 shows that age of most of the respondent was 8 - 10 years (48.8\%), 11 - 12 years (38.1\%) and 5 - 7 years $(13.1 \%)$. Respondents read in class five $(41.7 \%)$, in class four $(33.3 \%)$, in class three $(11.9 \%)$ and class two (13.1\%). The majority of the respondent father education levels are primary (14.3\%) and SSC (17.9), HSC (20.2), Degree/Honors (29.8) and 8.3\% are illiterate. The family monthly income is less than 12,000 tk (46.4\%) and more than 12,000 tk (53.6\%). Most of the family use tube well (38.1\%) and Tap water (42.9\%) as source of drinking water.

\section{Discussion}

This study highlighted the major's contagious diseases in the children of Tangail city. It was found that some of these contagious diseases strongly affect the nutritional status of the children. In infected group more than half 
Table 1. Frequencies and percentages of hygiene and sanitary condition of respondent's family.

\begin{tabular}{|c|c|c|c|}
\hline Variables & Categories & Frequency & Percent \\
\hline & Bad & 4 & 4.8 \\
\hline \multirow[t]{3}{*}{$\begin{array}{l}\text { Hygiene and sanitary condition } \\
\text { of respondents home toilet }\end{array}$} & Satisfactory & 41 & 48.8 \\
\hline & Better & 39 & 46.4 \\
\hline & Hygienic & 14 & 16.7 \\
\hline \multirow[t]{3}{*}{ Environment of respondents school } & Unhygienic & 18 & 21.4 \\
\hline & Satisfactory & 52 & 61.9 \\
\hline & Bad & 18 & 21.4 \\
\hline \multirow{4}{*}{$\begin{array}{l}\text { Hygiene and sanitary condition } \\
\text { of respondents school toilet }\end{array}$} & Satisfactory & 57 & 67.9 \\
\hline & Better & 9 & 10.7 \\
\hline & Soap/bar & 31 & 36.9 \\
\hline & Detergent & 15 & 17.9 \\
\hline \multirow[t]{4}{*}{$\begin{array}{l}\text { Respondent family } \\
\text { washes utensils with }\end{array}$} & Ash & 15 & 17.9 \\
\hline & Simply water & 10 & 11.9 \\
\hline & Ash mixed with detergent & 13 & 15.5 \\
\hline & 3 - 5 days & 25 & 29.8 \\
\hline \multirow[t]{3}{*}{$\begin{array}{l}\text { Interval of washing } \\
\text { respondents cloth }\end{array}$} & 6 - 9 days & 41 & 48.8 \\
\hline & 10 - 15 days & 18 & 21.4 \\
\hline & Every day & 60 & 71.4 \\
\hline \multirow[t]{3}{*}{$\begin{array}{l}\text { Respondent use soap } \\
\text { during bathing }\end{array}$} & One times in two days & 19 & 22.6 \\
\hline & One times in three days & 5 & 6.0 \\
\hline & Pond & 19 & 22.6 \\
\hline \multirow[t]{3}{*}{ Respondent take bathe in } & Tube-well & 46 & 54.8 \\
\hline & Both pond and tube-well & 19 & 22.6 \\
\hline & Everyday & 60 & 71.4 \\
\hline \multirow[t]{3}{*}{ Respondent take bathe } & One day interval & 21 & 25.0 \\
\hline & Two days interval & 3 & 3.6 \\
\hline & Give extra care & 6 & 40 \\
\hline \multirow{3}{*}{$\begin{array}{l}\text { Role of respondents } \\
\text { family during disease occurred }\end{array}$} & Separate from others & 3 & 20 \\
\hline & Show normal behavior & 3 & 20 \\
\hline & Change diet and utensil & 3 & 20 \\
\hline
\end{tabular}




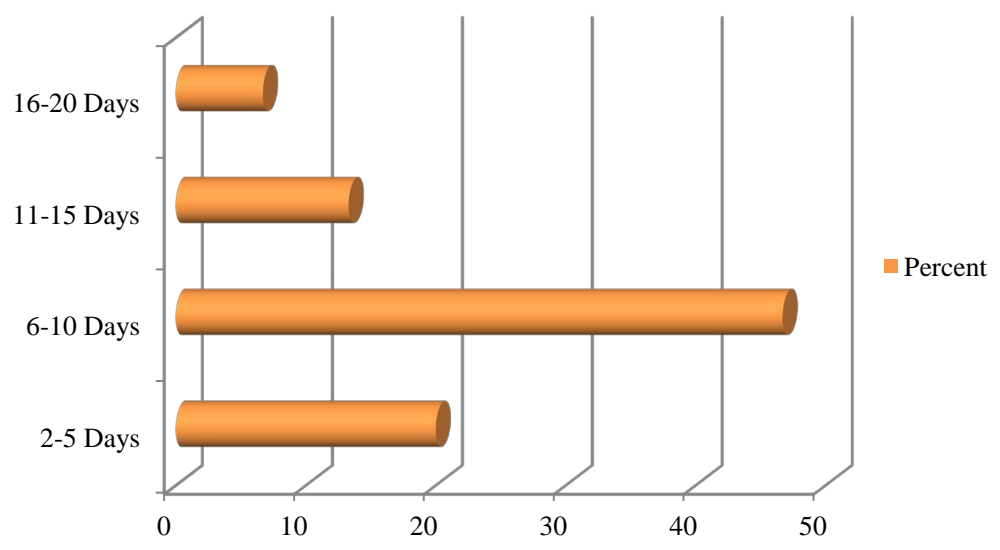

Figure 3. Time period of recovery from contagious disease.

\section{Percent}

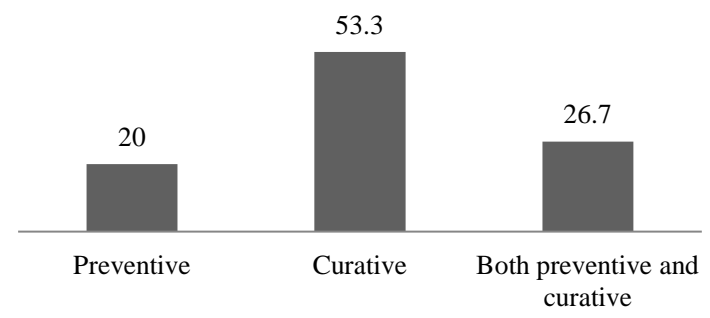

Figure 4. Type of service which they provide.

Table 2. Frequencies and percentages of nutritional and feeding condition.

\begin{tabular}{|c|c|c|c|}
\hline Variables & Categories & Frequency & Percent \\
\hline \multirow{4}{*}{ Condition of the respondents } & Well-nourished & 41 & 48.8 \\
\hline & Underweight & 18 & 21.4 \\
\hline & Stunted & 15 & 17.9 \\
\hline & Wasted & 10 & 11.9 \\
\hline \multirow{4}{*}{$\begin{array}{l}\text { Respondent suffering from } \\
\text { the deficiency of micronutrient }\end{array}$} & Vitamin & 19 & 22.6 \\
\hline & Mineral & 12 & 14.3 \\
\hline & Combination of them & 11 & 13.1 \\
\hline & Have no deficiency & 42 & 50.0 \\
\hline \multirow{5}{*}{ Respondent take meal every day } & Two & 2 & 2.4 \\
\hline & Three & 21 & 25.0 \\
\hline & Four & 32 & 38.1 \\
\hline & Five & 17 & 20.2 \\
\hline & More than five & 12 & 14.3 \\
\hline \multirow{6}{*}{ Tiffin that are mainly at the school } & Cake, biscuits, & 26 & 31.0 \\
\hline & Chocolates and candy & 15 & 17.9 \\
\hline & Puffed rice and bread & 12 & 14.3 \\
\hline & Fruits & 6 & 7.1 \\
\hline & Yoghourt & 7 & 8.3 \\
\hline & Take no tiffin & 18 & 21.4 \\
\hline
\end{tabular}


Table 3. Frequencies and percentages of demographic condition of respondents.

\begin{tabular}{|c|c|c|c|}
\hline Variables & Categories & Frequency & Percent \\
\hline \multirow{3}{*}{ Age group of respondents } & $5-7$ years & 11 & 13.1 \\
\hline & 8 - 10 years & 41 & 48.8 \\
\hline & $11-12$ years & 32 & 38.1 \\
\hline \multirow{4}{*}{ Educational qualification of the respondent } & Class 2 & 11 & 13.1 \\
\hline & Class 3 & 10 & 11.9 \\
\hline & Class 4 & 28 & 33.3 \\
\hline & Class 5 & 35 & 41.7 \\
\hline \multirow{6}{*}{ Educational level of respondent's father } & Illiterate & 7 & 8.3 \\
\hline & Primary & 12 & 14.3 \\
\hline & SSC & 15 & 17.9 \\
\hline & HSC & 17 & 20.2 \\
\hline & Degree/Hon’s & 25 & 29.8 \\
\hline & Others & 8 & 9.5 \\
\hline \multirow{2}{*}{ Family monthly income (Taka) } & Lower income less than BDT 12,000 & 39 & 46.4 \\
\hline & Higher income more than BDT 12,00 & 45 & 53.6 \\
\hline \multirow{4}{*}{ Source of drinking water } & Tube well & 32 & 38.1 \\
\hline & Boiled water & 9 & 10.7 \\
\hline & Tap water & 36 & 42.9 \\
\hline & Bottled water & 7 & 8.3 \\
\hline
\end{tabular}

of the children were underweight, stunted or wasted. This may be a risk factor for them to easily attack by contagious diseases. It was also found that most of the children were suffering from scabies and then influenza, typhoid, chicken pox, measles, pneumonia, whooping cough and more than $46 \%$ respondent recovered from disease within 6 - 10 days. Most of the respondent (53.3\%) took curative treatment during affected by contagious disease. Only (20\%) took preventive and some took both curative and preventive (26\%) treatment to prevent contagious disease. The percentages of hygiene and sanitary condition of respondent's family was not good, about $48.8 \%$ respondents home toilets condition was in satisfactory level but in school $21.4 \%$ was bad. Approximately half of the respondent washed their cloths 6 - 9 day interval which may be a major risk factor to attack by contagious disease. Most of the respondent bathed in Tube-well and some used pond (22.4\%). About $40 \%$ respondent got extra care from their family during infected disease. About $26 \%$ children were suffered from vitamin deficiency, about 14\% suffered from mineral deficiency and $13.3 \%$ suffered from both vitamin and mineral deficiency but 50\% children have no vitamin and mineral deficiency. About 38.1\% respondents took their meal four times in a day and 25\%, 20.2\% respondent took meal in five times and three times respectively. Maximum respondent (31\%) had their tiffin at the school with biscuit, cake. Most of the respondent's family used tube well (38.1\%) and tap water (42.9\%) as source of drinking water.

\section{Conclusion}

The prevalence of contagious diseases is a problem of affluent children going to various public schools in Tangail City of Bangladesh. But comparing with other studies, the rate of contagious diseases seems to be less in Tangail, though the data available on childhood contagious diseases are patchy and sometime difficult to compare as the food habits and other life styles vary greatly across the country. The criteria prescribed by CDC, Atlanta is arguable a better index for finding contagious diseases as this is age and sex specific. Prevalence of con- 
tagious disease especially influenza, and scabies was high among lower primary school children in the study area. This might be a reflection of the prevalence in the overall population of the area. Thus similar population based studies could be useful in estimating the burden of the condition and formulating appropriate strategies. We recommend steps to increase knowledge, attitude and practice among children regarding contagious disease. They should be taught about risk factors for contagious disease, control and prevention. Significance of timely detection and treatment should be stressed in school health programs. Child to child education program could be advocated for propagating hygienic habits in schools. Topics like personal hygiene and prevention of contagious diseases could be integrated into school health club activities in the form of projects, seminars, poster exhibitions etc. Parents should also be educated regarding skin disease. Parent teacher association could serve as a suitable stage for discussing these issues. Infrastructure development and environmental hygiene are vital. Overall coverage and quality of school health checkups should be improved. Adequate emphasis should be given for training of doctors and community health workers in diagnosing and managing common dermatological conditions.

\section{References}

[1] WHO (2001) Protocol for the Assessment of National Communicable Disease Surveillance and Response Systems. Guidelines for Assessment Team. World Health Organization. Department of Communicable Disease Surveillance and Response.

[2] WHO (2006) Communicable Disease Surveillance and Response Systems, a Guide to Planning.

[3] Ministry of Health (Sudan) (1996) Epidemiology Department. A Report of Strategic Plan for National Communicable Disease Surveillance in Sudan, Khartoum.

[4] Abdoulaye, D., Adama, Z.D., Vanessa, M., Ousmane, T., Diarra, S.N., Abdoulaye, K., Ongoiba, A. and Ogobara, D. (2015) Urban Schistosomiasis and Associated Determinant Factors among School Children in Bamako, Mali, West Africa. Infectious Diseases of Poverty, 4, 4. http://dx.doi.org/10.1186/2049-9957-4-4

[5] Chin, J. (2011) Control of Communicable Diseases Manual. 17th Edition, The Ministry of Planning, Washington. Population and Housing Census. Bangladesh Bureau of Statistics Statistics and Informatics Division.

[6] WHO (1998) Regional Office for Africa. A Regional Strategy for Communicable Diseases (1999-2003). Tenth Meeting.

[7] David, P. and Haberlen, S. (2005) 10 Best Resources for Measuring Population Health. Health Policy and Planning Journal, 20, 260-263. http://dx.doi.org/10.1093/heapol/czi030

[8] Ghag, S. (2002) Role of Infection Control Nurse in the Surveillance of Nosocomial Infections. Nursing Journal of India, 93, 57-58.

[9] Protocol for the Evaluation of Epidemiological Surveillance Systems (1997) Health Protection Agency. What Is Communicable Diseases Surveillance.

[10] Health Protection Agency (2006) What Is Communicable Diseases Surveillance.

[11] Olaseha, I.O. and Sridhar, M.K. (2005-2006) Participatory Action Research: Community Diagnosis and Intervention in Controlling Urinary Schistosomiasis in an Urban Community in Ibadan, Nigeria. International Quarterly of Community Health Education, 24, 153-160. http://dx.doi.org/10.2190/CBYM-94N2-E7DH-QRAL

[12] Ministry of Planning. Population and Housing Census (2011) Bangladesh Bureau of Statistics Statistics and Informatics Division. 